\title{
"They Did Not Walk the Green Talk!:" How Information Specificity Influences Consumer Evaluations of Disconfirmed Environmental Claims
}

\author{
Davide C. Orazi ${ }^{1}$ Eugene Y. Chan ${ }^{1}$
}

Received: 19 December 2017 / Accepted: 26 September 2018 / Published online: 4 October 2018

(c) The Author(s) 2018

\begin{abstract}
While environmental claims are increasingly used by companies to appeal consumers, they also attract greater scrutiny from independent parties interested in consumer protection. Consumers are now able to compare corporate environmental claims against external, often disconfirming, information to form their brand attitudes and purchase intentions. What remains unclear is how the level of information specificity of both the environmental claims and external disconfirming information interact to influence consumer reactions. Two experiments address this gap in the CSR communication literature. When specific (vs. vague) claims are countered by specific (vs. vague) external information, consumers report more negative brand attitudes and lower purchase intentions (Experiment 1). The effect is serially mediated by (1) skepticism toward the claims and (2) lack of corporate credibility (Experiment 2). We conclude by discussing strategies that firms can utilize to avoid information dilution and ensure that external disconfirming information percolates to consumers as specific.
\end{abstract}

Keywords CSR communications · Corporate credibility · Environmental claims · Green skepticism · Information specificity level

\section{Introduction}

As consumers place a premium on green products (Luchs and Kumar 2017) and environmental friendliness (Katsikeas et al. 2016; Brulhart et al. 2017), companies worldwide increasingly use environmental claims as part of their Corporate Social Responsibility (CSR) communication strategy (Parguel et al. 2011; Marquis and Qian 2013). At the same time, the use of environmental claims attracts scrutiny by parties interested in protecting consumers, such as federal regulatory bodies, NGOs, and media (Parguel et al. 2011). These agents constantly monitor and verify companies' environmental claims-often disconfirming them when they do not live up to their claims. A notable example is the September 2015 Volkswagen emissions scandal: the automaker touted its environmental friendliness yet was

Davide C. Orazi

Davide.Orazi@monash.edu

1 Department of Marketing, Monash Business School, Monash University, 26 Sir John Monash Dr., Caulfield East, VIC 3145, Australia proven otherwise by the U.S. Environmental Protection Agency (EPA) after it was found that VW had programmed TDI diesel engines to activate emissions controls only during laboratory emissions testing. This heightened media scrutiny has contributed to increasing consumer skepticism about how green a company may be (Becker-Olsen et al. 2006; Mohr et al. 1998).

The communication of clear and specific environmental claims has thus become a regulatory imperative. Many federal regulatory bodies discourage or sometimes even ban the use of environmental claims that are vague on the account that they mislead consumers. According to the U.S. Federal Trade Commission (FTC), vague environmental claims should be avoided, or the least be substantiated with competent and reliable scientific evidence (16 C.F.R. § 260.7). In Europe, Article 6(1; a) and (b) of the Unfair Commercial Practices Directive emphasizes the need for clear, truthful, and accurate information. These regulations are backed up by research demonstrating the misleading effects of vague claims (Wagner et al. 2009). However, aside from complying with federal regulations, companies often tout their environmental friendliness clearly and specifically to improve the persuasiveness of 
their claims to consumers. The degree to which claims are specific or vague is referred to as the information specificity level.

While previous research has shed light on the persuasiveness corporate environmental claims depending on level of information specificity (Wagner et al. 2009), such investigations have not taken into account the information specificity of the external disconfirming information. The CSR communication research has called for a deeper understanding of how consumers use independent information to inform their evaluations of environmental claims (Balmer et al. 2007; Parguel et al. 2011). Just like environmental claims, disconfirming information from third parties can be specific or vague, depending on the external informational environment of the firm (e.g., level of media scrutiny, communication channel mix used; see Lyon and Montgomery 2013). From a CSR communication perspective, it is thus vital to understand how the specificity level of external disconfirming information influences consumers' responses to corporate environmental claims.

Answering the call for more CSR communication research on the role of external information in consumer evaluation of environmental claims (Balmer et al. 2007; Parguel et al. 2011), this research sets out to explore how the information specificity levels of both corporate environmental claims and external disconfirming information interact to influence consumer band evaluations and purchase intentions of green products. In two behavioral experiments, we provide evidence that the level of information specificity (vague vs. specific) of environmental claims and external disconfirming information interact to affect consumers' brand attitudes and purchase intentions. We propose that external disconfirming information is unlikely to affect consumers' brand attitudes and purchase intentions in response to vague environmental claims whether the disconfirming information is vague or specific. But when environmental claims are specific, specific disconfirming information may be more effective in increasing skepticism and lowering credibility than vague third party information. Furthermore, we provide evidence for a serial mediating mechanism passing through (1) skepticism toward environmental claims made by companies and (2) credibility toward the companies themselves.

The remainder of the paper is organized as follows: First, we discuss the empirical literature on environmental claims and present the theoretical development for our hypotheses. We then discuss the methods and results of the two experiments. In Experiment 1, we test the interaction effect of information specificity level between environmental claims and external disconfirming information on consumers' brand attitudes and purchase intentions. In Experiment 2, we provide process evidence that the interactive effect of information specificity is serially mediated by, firstly, skepticism toward environmental claims and, secondly, credibility toward the company.

Our work offers important theoretical contributions to CSR communication research (Balmer et al. 2007; Parguel et al. 2011; Nyilasy et al. 2014) and also the consumer skepticism literature (Ford et al. 1990; Obermiller and Spangenberg 1998) in reference to how consumers integrate competing pieces of information when evaluating environmental claims. Beyond the theoretical contributions, we also support public policy by empirically testing various scenarios in which consumers react to specific or vague environmental claims followed by specific or vague disconfirming information. Moreover, we offer actionable communication strategies to avoid information dilution and to also ensure that the disconfirmation of environmental claims percolates to consumers as specific. We will conclude by discussing the limitations of our studies as well as future research avenues.

\section{Literature Review}

\section{CSR Communications and Environmental Claims}

In the last two decades, companies across the world have heavily invested in CSR communication (Hutton et al. 2001), defined as the set of advertising strategies aimed at presenting an ethical and responsible corporate identity (Balmer et al. 2007; Parguel et al. 2011). Many companies have specifically focused on ethical product differentiation-a particular approach to CSR communications based on differentiating a company's offerings on grounds of social or environmental sustainability (van de Ven 2008). For instance, Tesla and The Body Shop place environmental sustainability at the core of their positioning strategy (Forbes 2017). This particular CSR communication strategy, known as proactive communication (see Kang et al. 2016), consists of stating environmental claims upfront to protect corporate value against the reputational consequences caused by future adverse events (Minor and Morgan 2011). Proactive environmental communications are thus distinct from reactive environmental communications, the latter typically following environmental crises as means of reparation (Kang et al. 2016).

While recent CSR research demonstrates that environmental proactivity has a positive effect on financial profitability (Brulhart et al. 2017), firms are unlikely to benefit financially in the event of negative corporate environmental performance (Kang et al. 2016) - that is, in the eventuality that adverse events disconfirm the environmental claims made. Consumer reactions tend to be negative when an environmental claim is disconfirmed by external evidence, rather than when a negative environmental event (e.g., the BP Oil spill) is followed by an apology and the promise of 
future environmental commitment (Wagner et al. 2009). In other words, when the firm's claims are disconfirmed by negative evidence on the firms' corporate environmental performance, consumers react more negatively because the distance between the claims and the negative evidence is perceived as corporate hypocrisy (Wagner et al. 2009). Table 1 summarizes the selected literature dealing with consumer reactions to different environmental communication strategies.

Beyond the fact that consumers react negatively to the disconfirmation of corporate environmental claims, however, little do we know about the role that is played by independent information proffered by third parties. Thus, Balmer et al. (2007) have called for more research on the role of independent information that consumer access through digital technology and compare against corporate claims. Yet, the only investigation on the effect of independent information looks at how consumers use independent sustainability ratings to form evaluations following corporate claims (Parguel et al. 2011). Beyond insights offered by this single study, we do not know how information specificity levels of both the environmental claims as well as the external disconfirming information might influence consumer reactions.

\section{Specificity of Environmental Claims and Regulations}

In reference to environmental claims, companies can claim, for example, that they produce products from renewable sources and thus specifically state what they do to be environmentally friendly (e.g., "we only use non-toxic chemicals in the production of our recycled paper") or vaguely that they are "environmentally friendly," "green," or the like. Vague claims, however, can mislead consumers into thinking that a company is "green" when it may not be. Precisely for this reason, environmental regulators look suspiciously at vague claims. To protect consumers, the U.S. Federal Trade Commission Guidelines (2012) rule that marketers should refrain from making general and vague environmental claims, for instance "eco-friendly" as these claims cannot be easily substantiated and are open to different interpretations. Instead, marketers should "qualify general environmental benefit claims to focus consumers on the specific environmental benefits that they can substantiate. In doing so, marketers should use clear and prominent qualifying language to convey that a general environmental claim refers only to a specific and limited environmental benefit(s)" (Federal Register 2012, p. 62122). On a similar note, the U.S. Patent and Trademark Organization forbids companies from using the vague connotative "green" in trademarks unless they can prove their environmental friendliness (Sundar and Kellaris 2016).

Regulations on the communication of environmental claims thus discourage the use of vague environmental claims. Yet, even when the firm claims to be "green" in specific terms, we contend that consumer reactions to the disconfirmation of such claim will vary depending on the specificity of the external information. We build on Lyon and Montgomery's (2013) contention that external information can be vague or specific to derive a theory of information specificity in green CSR communications.

\section{Hypotheses Development}

\section{The Information Specificity of Environmental Claims and External Disconfirming Information}

External disconfirming information that counters corporate environmental claims can similarly vary in their level of specificity, as do environmental claims, based on factors such as the information environment of the firm, the communication mix channel, and media scrutiny (Lyon and Montgomery 2013). Depending on these factors, external information can arrive to consumers as specific, such as coverage that the company in question does not make products from renewable sources (if the company claims so), or vague, such as information suggesting that a firm is merely "not green" without any evidence of how or why it is not so. In the current research, we contend that how consumers form brand attitudes and purchase intentions when environmental claims are disconfirmed by external, third-party information should depend on the information specificity (vague vs. specific) of environmental claims and the external information that disconfirms those claims.

In reference to corporate environmental claims, current regulations argue that vague claims can mislead consumers into thinking that a company is more "green" than it actually is (FTC 2012). For example, the claim "we are environmentally friendly" is misleading without offering more specific evidence to back up such a claim. But just like how vague environmental claims can mislead consumers to think that a company is more "green" than it actually may be (attracting the frowns of regulatory bodies), vague disconfirming information would similarly allow room for doubt in consumers regarding the veracity of vague disconfirming information.

In the persuasion literature, vague claims give consumers room to more easily assimilate or integrate how the subsequent, supposedly contradicting information may or may not co-exist with those initial attitudes (Fabrigar and Petty 1999; Muthukrishnan et al. 1999). Literature on judgment revision best informs this hypothesis. Pham and Muthukrishnan (2002) argued that the extent to which information is commensurable influences the revision of judgments. They argued that vague initial judgments undergo less judgment revision in the face of specific information because the information incompatibility 


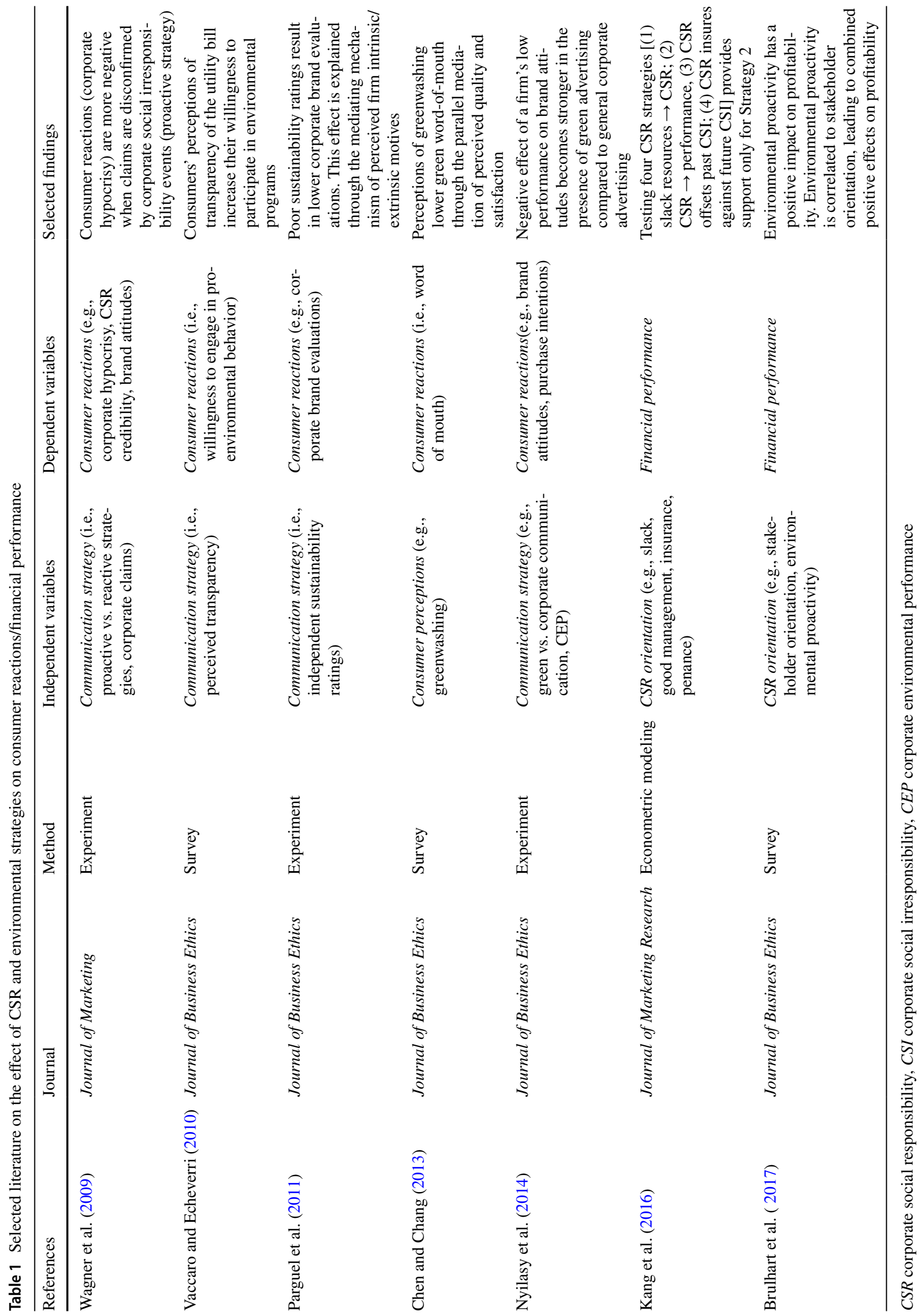


makes it harder for consumers to see the specific counter information as indeed countering the initial judgment.

As specific environmental claims provide a definite (supposed) account of a firm's environmental endeavors, we proffer that only specific (vs. vague) disconfirming information from a third party would lead to more harsh consumer responses-namely more negative brand attitudes and lower purchase intentions. Consider a specific environmental claim such as "We make our products from renewable sources." Specific external information such as "The company does not produce products from renewable sources" would directly disconfirm the firm's environmental claims, leading to more negative attitudes. This contention is in line with how direct countering evidence is more effective in persuasion (Fabrigar and Petty 1999; Petty and Cacioppo 1986; Pham and Muthukrishnan 2002; Snyder 1989). In contrast, vague external information such as "The company is not environmentally friendly" would provide less precise counter-arguments against specific environmental claims. The vagueness of such information allows consumers to reason, for instance, that the company never claimed to be environmentally friendly "generally" but it may be so in some other manner. The ensuing incompatibility between a specific claim and a vague disconfirmation provides consumers with more room for legitimate doubt, decreasing consumers' negative reactions.

However, when the environmental claims are vague, there should be no differences in consumers' brand attitudes or purchase intentions whether external disconfirming information is specific or vague. When external information is vague, it clearly would not discount the (vague) environmental claims made by corporations as it offers no credible evidence. But when external information is specific, such as when consumer protection agencies find that a firm does not produce products from renewable sources despite the firm claiming that they are "green," the consumer could conceivably reason that the firm could be green in other respects. The vagueness of the environmental claims offers room for consumers to perceive specific information to be not as contradictory to environmental claims as third party agents may intend (Bless and Schwarz 2010; Pham and Muthukrishnan 2002). In summary, we expect that the information specificity of external information moderates the effect of information specificity of environmental claims on brand attitudes and purchase intentions, such that:

Hypothesis 1 When environmental claims are specific, specific (vs. vague) disconfirming information will lead to lower (a) brand attitudes and (b) purchase intentions, whereas when environmental claims are vague there will be no difference on the basis of the specificity of external disconfirming information.

\section{Skepticism Toward the Claim, Credibility Toward the Company}

Beyond exploring how specific or vague external information moderates the effect of specific or vague environmental claims on consumer reactions, we seek to unearth the process mediating the effect. Prior research points to green skepticism - or the disbelief about corporate claims praising the environmental performance of a green offering (Mohr et al. 1998; Becker-Olsen et al. 2006)—as a likely response to potentially misleading or false green claims (Nyilasy et al. 2014). However, prior CSR research has mainly measured and modeled the antecedents of green skepticism, such as perceptions of CSR, corporate history, norms in the industry, intrinsic motives (Leonidou and Skarmeas 2015), environmental concerns (do Paço and Reis 2012), and green consumerism (Matthes and Wonneberger 2014). There is limited prior CSR research that use experimental methods to test the link between environmental claims or external information and green skepticism, with two notable exceptions. Nyilasy et al. (2014) studied effects of claims disconfirmed by evidence of low corporate environmental performance. Parguel et al. (2011) investigated the effect of how consumers use sustainability ratings to form their evaluations of environmental claims. Neither study, however, delves deeper into the information specificity of either environmental claims or external information.

In addition to a paucity of experimental research, CSR communication research does not distinguish between different skepticism types. Negative consumer responses to communications can be differentiated on the basis of the focal object being the environmental claims or the firm that is making them. Skepticism refers to distrust of marketing communications (Ford et al. 1990; Forehand and Grier 2003; Obermiller and Spangenberg 1998; Webb and Mohr 1998); credibility refers to distrust of the source of the communications (Forehand and Grier 2003). We anticipate that the interactive effect in Hypotheses 1 applies to green skepticism and corporate credibility as well. Specifically, when environmental claims are specific, specific external information should increase skepticism toward the claims and lower corporate credibility in serial, whereas vague external disconfirming information will create an informational incompatibility facilitating room for doubt, thus reducing green skepticism and increasing corporate credibility. But when green claims are vague, the information specificity of external information should not matter as it will not directly contradict the claims (Bless and Schwarz 2010). In summary, we expect that the information specificity of external disconfirming information moderates the effect of information specificity of environmental claims on green skepticism and corporate credibility. More formally stated: 
Fig. 1 Theoretical model

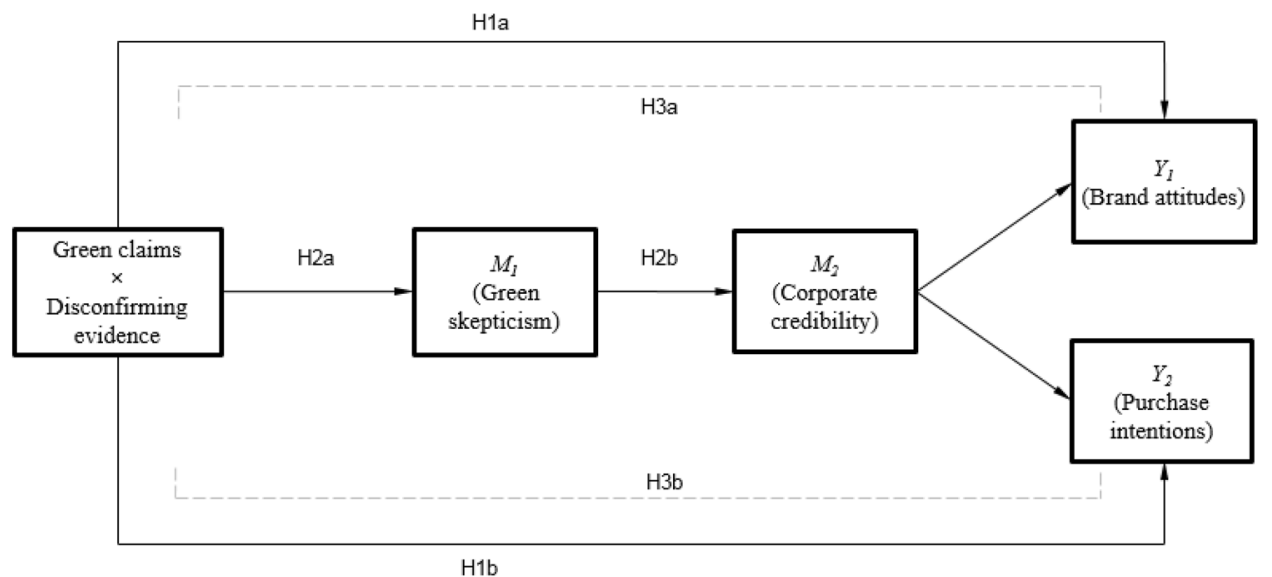

Hypotheses summary: H1: Significance of the interactive effect on (a) brand attitudes and (b) purchase intentions

H2: Significance of the interactive effect on (a) green skepticism and (b) corporate credibility

H3: Significance of the indirect interactive effect on (a) brand attitudes and (b) purchase

intentions through green skepticism and corporate credibility

Hypothesis 2 When environmental claims are specific, specific (vs. vague) disconfirming information will lead to (a) higher green skepticism and (b) lower corporate credibility, whereas when environmental claims are vague there will be no difference on the basis of the specificity of external disconfirming information.

So far, Hypotheses 1 and 2 articulate our prediction on the interactive effect of the specificity of environmental claims and external disconfirming information on green skepticism, corporate credibility, brand attitudes, and purchase intentions. We furthermore believe that this interactive effect might influence brand attitudes and purchase intentions through the underlying mechanisms of green skepticism and corporate credibility. However, while skepticism and credibility are similar in that they both refer to perceptions of distrust, the object of skepticism is the communication (Ford et al. 1990; Forehand and Grier 2003; Obermiller and Spangenberg 1998; Webb and Mohr 1998) while the object of credibility is the source of the communications (Forehand and Grier 2003).

We thus contend that skepticism toward the claims should come first, and then inform consumers' perceived credibility about the company. If no prior attitudes toward the source exist (such as for new companies), consumers rely on any other available cue to inform their judgment (Gigerenzer and Gaissmaier 2011; Payne et al. 1991). Where the company making the green claims is new to consumers, the only "cue" on which they can rely to form an initial judgment would be those environmental claims. Therefore, skepticism toward environmental claims should spill onto perceptions of corporate credibility. Formally stated:
Hypothesis 3 The interaction effect between the information specificity of environmental claims and external disconfirming evidence on (a) brand attitudes and (b) purchase intentions will be serially-mediated by green skepticism (1st mediator) and corporate credibility (2nd mediator).

Figure 1 depicts the theoretical model and summarizes the hypotheses.

\section{Experiment 1: The Information Specificity of Environmental Claims and Disconfirming Information}

The purpose of Experiment 1 was to test the interactive effect detailed in Hypothesis 1, namely that the informational specificity of both corporate environmental claims and external disconfirming information interact to affect both brand attitudes and purchase intentions.

\section{Method}

\section{Participants and Design}

We recruited 160 Americans from Amazon Mechanical Turk $\left(M_{\text {age }}=34.76\right.$ years old, $\mathrm{SD}=11.75$ years old; 83 males, 77 females). We employed a 2 (environmental claims: vague, specific) $\times 2$ (external information: vague, specific) betweenparticipants design. 


\section{Stimulus Development}

We developed stimulus materials using a fictitious brand to avoid confound effect stemming from familiarity. Participants received information about a fictitious furniture company "Oaky" that purportedly makes furniture with sustainable resources (specific) or claimed to be friendly to the environment (vague). They also saw information ostensibly from an independent testing agency stating that the company either did not produce furniture using non-sustainable materials (specific) or was not environmentally friendly (vague). All information was presented in written format on the same webpage to simulate the fact that consumers often become aware of corporate environmental claims and external disconfirming information on the same web or social media page, and can compare both pieces of information simultaneously. The experimental stimuli are included in Appendix 1.

\section{Dependent Measures}

After exposure to the experimental stimuli, participants reported their purchase intentions on a 7-point item adapted from Mitchell and Olson (1981) and widely used in marketing research (Bergkvist and Rossiter 2007). Next, participants reported their brand attitudes $(\alpha=0.97)$ on a 3-item, 7-point Likert scale by Muehling and Laczniak (1988). Participants then completed manipulation checks for the information specificity of environmental claims ("Thinking about the claims made by Oaky of their environmental friendliness, do you think these claims were vague or specific?") and external information ("Thinking about the external information countering Oaky's claims, do you think this information was vague of specific?") on 7-point Likert scales, sand provided sociodemographic information. Appendix 2 presents the items for all the measures employed.

\section{Results}

\section{Manipulation Checks}

The manipulation check for environmental claims was successful: participants in the vague claims condition reported that the claims were more vague compared to participants in the specific claims condition $\left(M_{\text {vague_claims }}=3.11, \mathrm{SD}=1.78\right.$ vs. $M_{\text {specific_claims }}=4.90, \mathrm{SD}=1.81 ; F[1,158]=39.56$, $p<0.001)$. The same pattern of results occurred for external disconfirming information $\left(M_{\text {vague_info }}=2.90, \mathrm{SD}=1.56\right.$ vs. $\left.M_{\text {specific_info }}=4.69, \mathrm{SD}=1.61 ; F[1,158]=50.69, p<0.001\right)$.

\section{Purchase Intentions}

A $2 \times 2$ ANOVA on purchase intentions indicated a significant interaction between environmental claims and external disconfirming information, $F(1,156)=7.35, p<0.01$. When environmental claims were specific, specific external information $(M=2.02, \mathrm{SD}=1.09)$ reduced purchase intentions compared to vague external information $(M=2.78$, $\mathrm{SD}=1.25), F(1,78)=12.88, p<0.01$. But, when environmental claims were vague, specific external information $(M=2.45, \mathrm{SD}=1.41)$ did not impact purchase intentions in comparison to vague information $(M=2.19, \mathrm{SD}=0.99$; $p=0.34$ ).

\section{Brand Attitudes}

The same ANOVA revealed a significant interaction crossing environmental claims and external disconfirming information, $F(1,156)=4.05, p<0.05$. For specific environmental claims, specific external information lowered brand attitudes $(M=1.86, \mathrm{SD}=1.32)$ compared to vague external information $(M=2.67, \mathrm{SD}=1.36), F(1,78)=7.11, p<0.01$. But for vague environmental claims, there was no effect of external information whether specific $(M=2.23, \mathrm{SD}=1.12)$ or vague $(M=2.26, \mathrm{SD}=1.03 ; p=0.91)$. Figure 2 presents the results.

\section{Discussion}

The results of Experiment 1 support H1, offering evidence for an interaction effect between the information specificity of both environmental claims and external disconfirming information on both brand attitudes and purchase intentions. As predicted, specific (vs. vague) external information has a differential impact on purchase intentions when countering specific, rather than vague, environmental claims. We now turn the processes underlying this interactive effect.

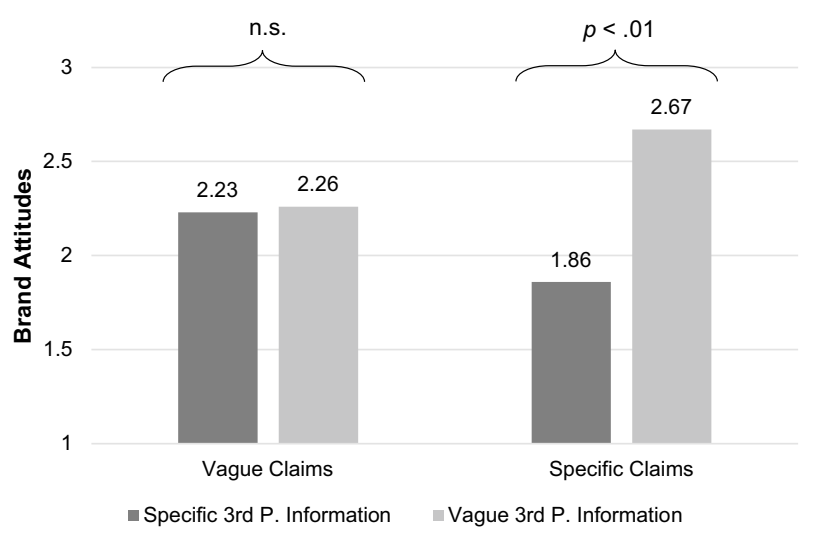

Fig. 2 Environmental Claims $\times$ External Information on Brand Attitudes (Exp. 1) 


\section{Experiment 2: Moderated Serial Mediation through Green Skepticism and Corporate Credibility}

Integrating and expanding on the preliminary insights offered by Experiment 1, Experiment 2 investigated whether green skepticism and corporate credibility serially mediates the interactive effect of environmental claims and external disconfirming information on brand attitudes and purchase intentions.

\section{Method}

\section{Participants and Design}

We recruited 210 Americans following the same procedures detailed in Study 1 ( $M_{\text {age }}=33.61$ years old, $\mathrm{SD}=10.37$ years old; 79 males, 131 females) and used a 2 (environmental claims: vague, specific) $\times 2$ (external information: vague, specific) between-participants design.

\section{Stimulus Development}

Participants were randomly assigned to either specific or vague environmental claims from a fictional paper company, "Green Co. Paper." The stimuli were a mix of text and pictures (see Appendix 1), with the text stating either that "We only use materials sourced from certified, sustainable suppliers: $100 \%$ recycled paper, energy efficient machinery, non-toxic chemicals" (specific) or that "We are an environmentally-friendly company" (vague). On the following screen, we presented participants with third party information: "Now imagine that you heard on the news that Green Co. Paper used materials sourced from non-certified, non-sustainable suppliers. This included non-recycled paper, energy inefficient machinery and toxic chemicals" (specific), or "Now imagine that you heard on the news that Green Co. Paper is not an environmentally friendly brand" (vague).

\section{Dependent Measures}

After exposure to the experimental stimulus, participants completed the same measures for purchase intentions (single item) and brand attitudes $(\alpha=0.98)$ as in Experiment 1 . They also completed 3-item, 7-point Likert scales measuring credibility toward the company $(\alpha=0.97$; Ohanian 1990) and skepticism toward the environmental claims $(\alpha=0.92$; Matthes and Wonneberger 2014). Manipulation checks and sociodemographic information were recorded last following the same procedures detailed in Experiment 1. Refer to Appendix 1 and 2 for more detail on both the stimuli and the measures employed.

\section{Results: Mean Differences}

\section{Manipulation Checks}

For environmental claims, participants in the vague condition reported that the claims were more vague $\left(M_{\text {vague }}\right.$ $=3.33, \mathrm{SD}=1.83)$ compared to participants assigned to the specific condition $\left(M_{\text {specific }}=4.91, \mathrm{SD}=1.57 ; F[1\right.$, $208]=45.02, p<0.001)$. For external information, the same pattern of results occurred $\left(M_{\text {vague }}=3.38, \mathrm{SD}=1.71\right.$ vs. $\left.M_{\text {specific }}=4.92, \mathrm{SD}=1.52 ; F[1,208]=47.33, p<0.001\right)$.

\section{Purchase Intentions}

A $2 \times 2$ ANOVA indicated that the two-way interaction was significant, $F(1,206)=7.35, p<0.01$. When environmental claims were specific, specific external information reduced purchase intentions $(M=2.19, \mathrm{SD}=1.02)$ compared to vague information $(M=3.36, \mathrm{SD}=1.52), F(1,105)=20.12$, $p<0.001$. But when the environmental claims were vague, specific external information did not impact purchase intentions $(M=2.39, \mathrm{SD}=1.71)$ compared to vague external information $(M=2.52, \mathrm{SD}=1.30 ; p=0.65)$.

\section{Brand Attitudes}

The two-way interaction was significant for brand attitudes also, $F(1,206)=7.98, p<0.01$. When environmental claims were specific, specific external information reduced brand attitudes $(M=2.10, \mathrm{SD}=1.35)$ compared to vague information $(M=3.40, \mathrm{SD}=1.59), F(1,105)=20.31, p<0.001$. But when the environmental claims were vague, specific external information did not influence purchase intentions $(M=2.02, \mathrm{SD}=1.22)$ compared to vague external information $(M=2.29, \mathrm{SD}=1.07 ; p=0.22)$.

\section{Corporate Credibility}

A $2 \times 2$ ANOVA indicated the interaction was significant for credibility as well, $F(1,206)=6.67, p<0.02$. When environmental claims were specific, specific external information reduced credibility $(M=1.97, \mathrm{SD}=1.20)$ compared to vague information $(M=3.04, \mathrm{SD}=1.53), F(1,105)=16.07, p<0.001$. However, when environmental claims were vague, external information did not affect credibility whether it was specific $(M=1.82, \mathrm{SD}=1.03)$ or vague $(M=2.03, \mathrm{SD}=1.05 ; p=0.31)$.

\section{Green Skepticism}

The $2 \times 2$ interaction was also significant for credibility, $F(1,206)=5.73, p<0.02$. When environmental claims 
were specific, specific external information raised skepticism $(M=5.90, \mathrm{SD}=1.07)$ compared to vague information $(M=4.84, \mathrm{SD}=1.42), F(1,105)=18.65, p<0.001$. But when environmental claims were vague, external disconfirming information did not affect skepticism whether it was specific $(M=5.92, \mathrm{SD}=1.05)$ or vague $(M=5.62, \mathrm{SD}=1.01 ; p=0.13)$.

\section{Results: Structural Equation Modeling and Process Evidence}

\section{Measurement Model}

To test our hypothesized model while also accounting for measurement error, we used structural equation modeling (SEM) with maximum likelihood estimation (software package: AMOS 22). A confirmatory factor analysis also allowed to ensure that all variables included in the model, in particular green skepticism and corporate credibility, exhibited both convergent and discriminant validity. Table 2 provides evidence of convergent validity, as all items loaded over 0.70 on their factors, with an average variance extracted (AVE) for each factor greater than 0.50 (Bagozzi et al. 1991). Table 3 provides evidence of discriminant validity, as the AVE of each construct was greater than the shared variance between each pair of constructs (Fornell and Larcker 1981). The measurement model achieved good fit $\left(\chi^{2} / d f=54.82 / 30=1.82 ; \mathrm{AGFI}=0.91 ; \mathrm{CFI}=0.99\right.$; RMSEA $=0.063$; PNFI $=0.65$ ).

\section{Structural Model}

Next, we tested the proposed structural model. To provide a more conservative test, we specified all the paths from the exogenous to the endogenous variables. The structural model achieved good fit $\left(\chi^{2} / d f=79.81 / 49=1.63\right.$; $\mathrm{AGFI}=0.90 ; \mathrm{CFI}=0.99 ; \mathrm{RMSEA}=0.055 ; \mathrm{PNFI}=0.61$ ). Figure 3 summarizes the overall serial moderated mediation model results with standardized estimates. Table 4 also offers a more detailed account of the unstandardized estimates for the structural model.

\section{Process Evidence}

In Hypothesis 3, we predicted that the interaction effect should first increase skepticism toward the environmental claims and then reduce credibility toward the company, with downstream negative effects on consumers brand evaluations and purchase intentions. We thus constructed bias-corrected confidence intervals with 10,000 bootstrapped samples (Hayes 2013) to test the significance of the indirect effect of environmental claims $\times$ external disconfirming information $\rightarrow$ green skepticism $\rightarrow$ corporate credibility $\rightarrow$ (a) brand attitudes; (b) purchase intentions. PROCESS model 6 was used
Table 2 Items, standardized factor loadings and measures of validity (Exp. 2)

\begin{tabular}{llll}
\hline Scale and scale items & $\beta$ & CR & AVE \\
\hline Green skepticism & & 0.922 & 0.797 \\
Green Co. Paper's claims are misleading & 0.893 & & \\
I do not believe Green Co. Paper's claims & 0.913 & & \\
Green Co. Paper's claims are not true & 0.871 & & \\
Corporate credibility & & 0.972 & 0.921 \\
Dishonest-Honest & 0.971 & & \\
Untrustworthy-Trustworthy & 0.974 & & \\
Insincere-Sincere & 0.934 & & \\
Brand attitudes & & 0.979 & 0.940 \\
Bad-Good & 0.962 & & \\
Unfavorable-Favorable & 0.972 & & \\
Negative-Positive & 0.974 & & \\
\hline
\end{tabular}

$\beta$ standardized factor loading, $C R$ composite reliability, $A V E$ average variance extracted

Table 3 Latent variables correlations and discriminant validity (Exp. 2)

\begin{tabular}{lcll}
\hline & Green skepticism & $\begin{array}{l}\text { Corporate } \\
\text { credibility }\end{array}$ & Brand attitudes \\
\hline Green skepticism & $\mathbf{0 . 7 9 7}$ & 0.712 & 0.540 \\
Corporate credibility & -0.844 & $\mathbf{0 . 9 2 1}$ & 0.683 \\
Brand attitudes & -0.735 & 0.827 & $\mathbf{0 . 9 4 0}$ \\
\hline
\end{tabular}

$r$ below the diagonal, $r^{2}$ above the diagonal in italic, AVE on the diagonal in bold

as the modified bias-corrected bootstrapping protocol (Hayes 2013), including the interaction terms as the independent variable, and both environmental claims and external disconfirming information as covariates. For brand attitudes, the total indirect effect was negative and significant $(B=-0.18 ; 95 \%$ CI -0.33 to -0.04 ), and this was mainly due to the serial mediation passing through green skepticism and corporate credibility ( $B=-0.12 ; 95 \% \mathrm{CI}-0.23$ to -0.02$)$. The total indirect effect of the interaction was also significant when purchase intentions were the dependent variable in the serial mediation model $(B=-0.13 ; 95 \% \mathrm{CI}-0.25$ to -0.03$)$.

\section{Tests of Reverse Causality}

Extant literature provides strong support for the contention that, for brands about which consumers do not hold pre-existing attitudes, consumers rely on available cues to inform their judgment (Gigerenzer and Gaissmaier 2011; Payne et al. 1991). As such, consumers form attributions of skepticism toward the claims, then use those attributions to inform overall perceptions of corporate credibility (Forehand and Grier 2003). Nevertheless, we tested for reverse causality, estimating a serial mediation model in which corporate 
Table 4 Unstandardized path estimates (Exp. 2-all paths specified)
Fig. 3 Structural model with standardized estimates (Exp. 2 -all paths specified). $* * * p$ value $<0.001 ; * * p$ value $<0.01$; $* p$ value $<0.05$. Dashed paths in gray represent non-significant relationships

\begin{tabular}{lllrrl}
\hline Specified paths & & & $B$ & SE & Sig. \\
\hline Env. claims $\times$ Disc. info & $\rightarrow$ & Green skepticism & 0.16 & 0.08 & $*$ \\
Env. claims $\times$ Disc. info & $\rightarrow$ & Corporate credibility & -0.08 & 0.05 & $p=0.151$ \\
Env. claims $\times$ Disc. info & $\rightarrow$ & Brand attitudes & -0.07 & 0.06 & $p=0.239$ \\
Env. claims $\times$ Disc. info & $\rightarrow$ & Purchase intentions & -0.12 & 0.08 & $p=0.133$ \\
Environmental claims & $\rightarrow$ & Green skepticism & -0.24 & 0.08 & $* *$ \\
Environmental claims & $\rightarrow$ & Corporate credibility & 0.07 & 0.05 & $p=0.225$ \\
Environmental claims & $\rightarrow$ & Brand attitudes & 0.05 & 0.06 & $p=0.389$ \\
Environmental claims & $\rightarrow$ & Purchase intentions & -0.02 & 0.08 & $p=0.840$ \\
Disconfirming information & $\rightarrow$ & Green skepticism & 0.35 & 0.08 & $* * *$ \\
Disconfirming information & $\rightarrow$ & Corporate credibility & -0.01 & 0.06 & $p=0.967$ \\
Disconfirming information & $\rightarrow$ & Brand attitudes & -0.10 & 0.06 & $p=0.077$ \\
Disconfirming information & $\rightarrow$ & Purchase intentions & -0.11 & 0.08 & $p=0.190$ \\
Green skepticism & $\rightarrow$ & Corporate credibility & -0.91 & 0.06 & $* * *$ \\
Green skepticism & $\rightarrow$ & Brand attitudes & -0.12 & 0.10 & $p=0.222$ \\
Green skepticism & $\rightarrow$ & Purchase intentions & -0.12 & 0.15 & $p=0.404$ \\
Corporate credibility & $\rightarrow$ & Brand attitudes & 0.75 & 0.09 & $* * *$ \\
Corporate credibility & $\rightarrow$ & Purchase intentions & 0.51 & 0.13 & $* * *$ \\
\hline
\end{tabular}

$* * * p$ value $<0.001, * * p$ value $<0.01, * p$ value $<0.05$

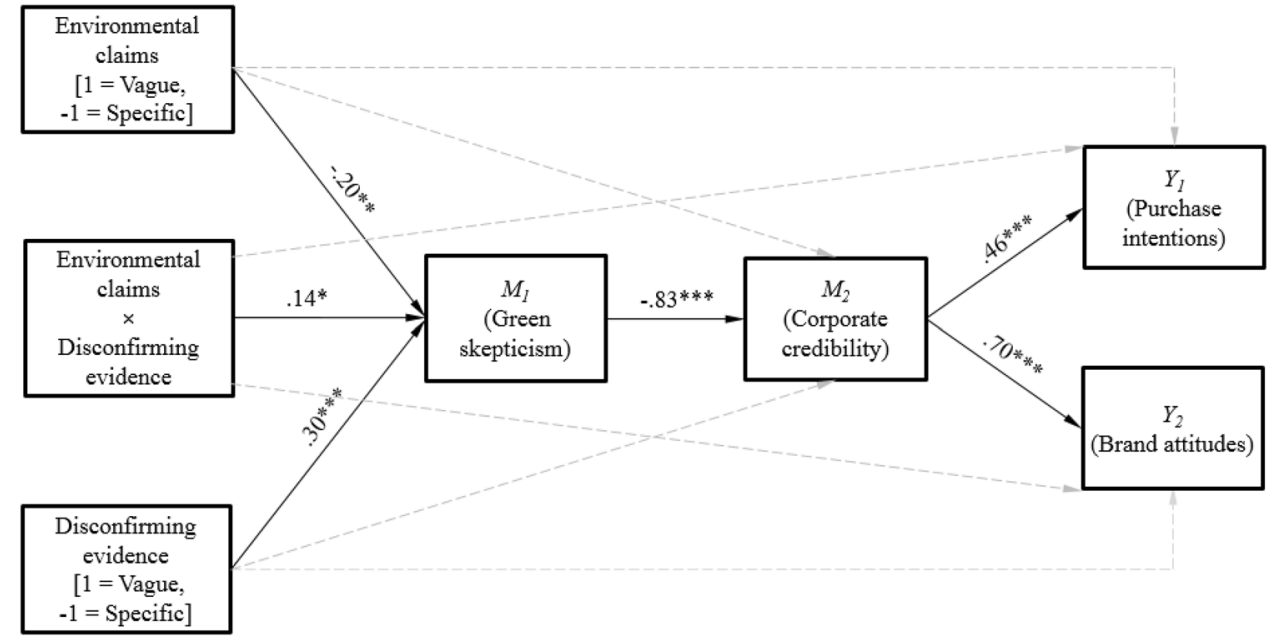

credibility was an antecedent to skepticism toward the environmental claims. As we had expected, when considering corporate credibility as the first mediator and skepticism as the second mediator, the serial mediation path was not significant $(B=-0.01 ; 95 \% \mathrm{CI}-0.05$ to 0.01$)$.

\section{Discussion}

Experiment 2 offers evidence that the levels of information specificity for both environmental claims and external disconfirming information interact with each other to affect skepticism toward the environmental claims and credibility about the source of the claims. H2A and H2B are thus supported. Moreover, our results provide evidence for a moderated serial mediation, such that the interactive effect is carried over by green skepticism first, and corporate credibility second. We also rule out the possibility of reverse causality, which is theoretically unlikely in a context in which consumers have no existing attitudes about the brand to guide their judgment and thus have to rely on the given information (in our case, the environmental claims). $\mathrm{H} 3$ is thus supported.

\section{General Discussion}

This research set out to investigate how the information specificity of both corporate environmental claims and external information from media, NGOs, and environmental agencies informs consumers' brand evaluations and purchase intentions, and the mechanisms that explain this effect. The 
experiments support our contention that, in green advertising contexts, specific (vs. vague) external information is most useful at increasing skepticism and reducing corporate credibility-but only when corporate environmental claims are specific. When environmental claims are vague, the specificity level of external disconfirming information has no effect. The interactive effect of information specificity of both the green claims and external disconfirming information on consumers' brand attitudes and purchase intentions are serially mediated by firstly green skepticism and then lack of corporate credibility. Our results offer key theoretical contributions as well as strategic insights for policymakers and independent agents monitoring the veracity of corporate environmental claims.

\section{Theoretical Contributions}

This research provides two substantive contributions to theory. First, we unveil the interactive effect of information specificity for both corporate environmental claims and external disconfirming information, which has great relevance to CSR communication research (Balmer et al. 2007; Parguel et al. 2011; Nyilasy et al. 2014). As noted by Parguel et al. (2011), 'the interaction between third parties' uncontrolled information and companies' controlled CSR communication may be strategic for determining consumers' attitude" (p. 17). Building on prior CSR communication research, this research contributes to a more nuanced understanding of the way consumers integrate environmental claims made by companies and external disconfirming information to form their brand evaluations and purchases. We thus enrich CSR communication research with a novel information specificity theory and, in so doing, extend the knowledge of information interactivity effects both in advertising and CSR communication specifically. Our findings indeed align with and extend prior research showing how direct countering evidence is most useful in persuasion (Fabrigar and Petty 1999; Petty and Cacioppo 1986). We suggest that this is also the case for external information that is vague - but only when environmental claims are also vague. Our research is thus situated within literature showing how initial attitudes or judgments vaguely formed might assimilate specific countering information (Bless and Schwarz 2010; Pham and Muthukrishnan 2002).

Second, in examining how consumers use external information to evaluate firms' environmental claims, we also extend the literature on consumer skepticism (Obermiller and Spangenberg 1998) and green skepticism in particular (Leonidou and Skarmeas 2015; Matthes and Wonneberger 2014; Nyilasy et al. 2014). Rather than considering consumers' attributions in terms of mere skepticism, we delve deeper to understand the full psychological process through which consumers inform their decisions after taking into account both environmental claims and external information. Our current results provide substantive evidence that consumers first form attributions of skepticism toward the environmental claims (i.e., green skepticism), and then transfer these attributions to the broader company making the claims (i.e., corporate credibility). Beyond the solid theoretical basis informing this contention, testing for reverse causality further supports the robustness of this finding.

\section{Practical Implications and Strategic Recommendations}

Our findings have also relevant implications for policy regulators, media, NGOs, and environmental agencies. The FTC Guidelines (2012) strongly advise against the use of unduly vague environmental claims, as they may be considered deceptive and incur legal liability. Our findings support the enforcement of the FTC Guidelines for environmental claims, empirically demonstrating the role played by information specificity in influencing consumer evaluations. Currently, regulatory bodies focus on the specificity level of companies' environmental claims themselves, which is useful in avoiding deception, but our findings suggest that the specificity level of disconfirming information by third parties also matters in affecting consumer skepticism and credibility. Even if companies use specific environmental claims to position their green offerings, in the eventuality that they do not live up the standards claimed, regulatory bodies need to ensure that specific and detailed accounts are released and circulated among consumers to avoid an attenuation effect. In an era of digital information in which external information is more than ever subject to consumer dilution and information overload effects (Scammon 1977; Lyon and Montgomery 2013), our findings echo the call of Parguel et al. (2011) for a more nuanced investigation of how external information percolates through to consumers and what can be done to ensure that external disconfirming information is as concrete as possible in order to achieve their consumer protection aims.

That said, our research does not test how to ensure that consumers access and retain specific disconfirming information. However, prior communication and advertising research provides useful guidelines in terms of presentation order, frequency, and media that can inform the communication strategies of NGOs and environmental agencies. With regard to presentation order, communication theory would suggest to leverage recency effects by presenting the critical argument (in this context case, the most specific details on episodes of corporate environmental irresponsibility) last as to increase retention of the information presented (Belchet al. 2012). With regard to exposure frequency, Schmidt and Eisend's (2015) meta-analysis suggested that an average of 3.5 exposures to the same message likely increase retention as well as subsequent recall. The authors however noted that this guideline is conditional on a number of factors, such as the level of involvement in the issue. For major 
environmental events such as the 2015 Volkswagen emission scandals, consumers may require less exposures to internalize and to remember the external information. Closely related to optimal frequency, Lyon and Montgomery (2013) suggested that social media might be a suitable media channel to circulate information on corporate environmental irresponsibility and greenwashing. Indeed, the network effects enabled by social media between relevant stakeholders allow information to go viral, naturally increasing the frequency of exposure to the same message (Lyon and Montgomery 2013).

\section{Limitations and Avenues for Future Research}

We did not test upfront for perceived credibility of external disconfirming information. Rather, we operated under the assumption that information coming from external sources tends to be more credible, in line with prior research stating that consumers assign higher credibility to external sources other than companies (Mohr et al. 2001; Obermiller and Spangenberg 1998), and are usually suspicious of green claims to begin with (Leonidou and Skarmeas 2015; Wagner et al. 2009). To be sure, we ran a series of post-test on the believability of external disconfirming information for both Experiment 1 and 2 . The results indicate that external information was perceived as more trustworthy than claims for both Experiment $1\left(M_{\mathrm{EDI}}=4.53, \mathrm{SD}=1.10 \mathrm{vs}\right.$. $\left.M_{\text {Claims }}=2.83, \mathrm{SD}=1.46 ; t[83]=7.56, p<0.001\right)$ and Experiment $2\left(M_{\mathrm{EDI}}=4.80, \mathrm{SD}=1.27\right.$ vs. $M_{\text {Claims }}=2.63, \mathrm{SD}=1.37$; $t[83)=9.62, p<0.001)$. A detailed account of the procedure and results are available in Appendix 3. Future research may extend these insights by manipulating the credibility of the source of external information. This information may stem from sources as diverse as NGOs, national media, and even consumers' tweets to assess whether consumers trust different sources of external information differently.

A second limitation is that we considered brand attitudes and purchase intentions as highly correlated, in the sense that our predicted effect would arise and the process would be the same for both dependent variables (Ajzen 1991). Although the findings of Experiments 1 and 2 confirm this notion when considering low-involvement product categories with low (i.e., paper) and medium price points (i.e., furniture), under different circumstances (e.g., high involvement, high-price points) this assumption may not hold true. Closely related, it is generally assumed that intentions lead to behaviors (Ajzen 1991). Future research should replicate our effect using real behavioral or choice measures, and extend the generalizability of our effects to high-price point product categories.

A third limitation is that we only test consumers' reactions to environmental claims that are subsequently disconfirmed by external information. Thus, we align with CSR communication research investigating proactive environmental communications (Nyilasy et al. 2014; Brulhart et al. 2017). Still, a possible extension of our work may be how the interactivity effect may differ when companies' environmental claims come after, as in a response to mitigate a negative crisis. Presentation order matters (Groza et al. 2011; Wagner et al. 2009). Reactively, consumers may be even more skeptical of environmental claims as they may perceive them as a way to protect profits and corporate image (Becker-Olsen et al. 2006; Groza et al. 2011). Along the same lines, consumers' guesses about the motives for environmental claims might be interesting moderating factors to investigate.

A promising avenue for future research might come from testing the influence of cognitive load and other distractions on how consumers assimilate information. Consumers increasingly acquire information on social media and are often (if not always) distracted by the multitude of perceptual cues offered by such platforms including chat boxes, ads, and other content. Researchers could test whether imposing a cognitive load between the presentation of environmental claims and that of external information, for instance checking a YouTube video on social media, would affect working memory and lead to an attenuation effect for information specificity. We hope this set of studies will stimulate an even more nuanced appreciation of how information specificity plays a critical role in influencing consumer evaluations of environmental claims and contradicting external information.

Acknowledgements We gratefully acknowledge the invaluable contribution of Gergely Nyilasy and input from Ann McGill on previous drafts of this manuscript.

\section{Compliance with Ethical Standards}

Ethics Approval All procedures performed in studies involving human participants were in accordance with the ethical standards of the institutional and/or national research committee and with the 1964 Helsinki declaration and its later amendments or comparable ethical standards. This project was approved by the Human Research Ethics Committee of the first author's former institution of affiliation with Ethics ID: 1442645 .

Informed Consent Informed consent was obtained from all individual participants included in the study.

Open Access This article is distributed under the terms of the Creative Commons Attribution 4.0 International License (http://creativeco mmons.org/licenses/by/4.0/), which permits unrestricted use, distribution, and reproduction in any medium, provided you give appropriate credit to the original author(s) and the source, provide a link to the Creative Commons license, and indicate if changes were made.

\section{Appendix 1: Experimental Stimuli}

See Figs. 4 and 5. 
Fig. 4 1A. Experiment 1 stimuli
Vague environmental claim Vague external information

- Oaky claims to be an environmentally friendly brand.

- At the same time, there's evidence that in reality Oaky has engaged in environmentally damaging behavior
Specific environmental claim

Vague external information

- Oaky claims to be an environmentally friendly brand. Specifically, they claim that they do not use wood from protected forests.

- At the same time, there's evidence that in reality Oaky has engaged in environmentally damaging behavior.

\section{Vague environmental claim Specific external information}

- Oaky claims to be an environmentally friendly brand.

- At the same time, there's evidence that in reality Oaky has engaged in environmentally damaging behavior. It was proven that they used wood from protected forests.

\section{Specific environmental claim Specific external information}

- Oaky claims to be an environmentally friendly brand.

Specifically, they claim that they do not use wood from protected forests.

- At the same time, there's evidence that in reality Oaky has engaged in environmentally damaging behavior. It was proven that they used wood from protected forests. 
Vague environmental claim

Vague external information

\section{GREEN CO, PAPER}

We are an environmentally friendly brand.

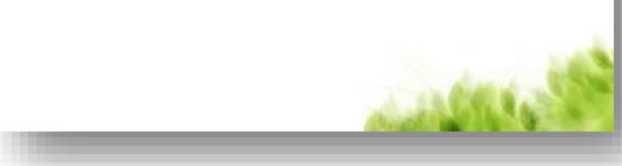

[NEXT SCREEN]

Now imagine that you heard on the news that Green Co. Paper is not an environmentally friendly brand.

Vague environmental claim Specific external information

\section{GREEN CO. PAPER}

We are an environmentally friendly brand.

[NEXT SCREEN]

Now imagine that you heard on the news that Green Co. Paper used materials sourced from non-certified, non-sustainable suppliers. This included non-recycled paper, energy inefficient machinery and toxic chemicals.
Specific environmental claim

Vague external information

\section{GREEN CO. PAPER}

We only use materials sourced from certified, sustainable suppliers: $100 \%$ recycled paper, energy efficient machinery, non-toxic chemicals.

[NEXT SCREEN]

Now imagine that you heard on the news that Green Co. Paper is not an environmentally friendly brand.

\section{Specific environmental claim} Specific external information

\section{GREEN CO. PAPER}

We only use materials sourced from certified, sustainable suppliers: $100 \%$ recycled paper, energy efficient machinery, non-toxic chemicals.

\section{[NEXT SCREEN]}

Now imagine that you heard on the news that Green Co. Paper used materials sourced from non-certified, non-sustainable suppliers. This included non-recycled paper, energy inefficient machinery and toxic chemicals.

Fig. 5 1B. Experiment 2 stimuli

\section{Appendix 2: Measures and Descriptive Statistics for All Experiments}

See Tables 5 and 6. 
Table 5 2A. Measures for all experiments

Purchase intentions: adapted from Mitchell \& Olson (1981); used in all experiments.

Imagine you were to buy [Exp. 1: furniture; Exp. 2: recycled paper]. How likely would you be to buy [Exp.

1: Oaky furniture; Exp. 2: Green Co. Paper] in the future?

Extremely unlikely to buy 1------2-------3------4-------5------6------7 Very likely to buy

Brand attitudes: adapted from Muehling \& Laczniak (1988); used in all experiments.

What is your attitude toward (brand name)?

$\begin{array}{ll}\text { Bad } & \text { 1------2------3------4------5------6------7 Good } \\ \text { Unfavorable } & \text { 1-------2-------3------4-------5------6------7 Favorable } \\ \text { Negative } & \text { 1------2-------3------4------5------6------7 Positive }\end{array}$

Green skepticism: adapted from Matthes \& Wonneberger (2014); used in Experiment 2.

In reference to the claims made by Green Co. Paper, rate your agreement with the following statements:

Strongly disagree Strongly agree

Green Co. Paper's claims are misleading.

$$
\begin{aligned}
& \text { 1------2------3------4------5------6------7 } \\
& \text { 1------2------3-------4------5------6------7 } \\
& \text { Green Co. Paper's claims are not true. } \quad \text { 1------2------3------4------5------6------7 }
\end{aligned}
$$

Credibility: adapted from Ohanian (1990); used in Experiment 2.

In reference to Green Co. Paper as a company, do you feel they are:

$\begin{array}{llll}\text { Dishonest } & \text { 1------2------3------4------5------6------7 Honest } \\ \text { Untrustworthy } & \text { 1-------2------3------4------5------6------7 } & \text { Trustworthy } \\ \text { Insincere } & \text { 1------2-------3------4------5------6------7 } & \text { Sincere }\end{array}$


Table 6 2B. Means and S.D.s for all experiments

\begin{tabular}{|c|c|c|c|c|}
\hline \multirow{2}{*}{$\begin{array}{l}\text { Environ. Claims } \\
\text { External Info }\end{array}$} & \multicolumn{2}{|l|}{ Vague } & \multicolumn{2}{|l|}{ Specific } \\
\hline & Vague & Specific & Vague & Specific \\
\hline \multicolumn{5}{|c|}{ Experiment 1: Oaky } \\
\hline Brand attitudes & $2.26(1.03)$ & $2.23(1.12)$ & $2.67(1.36)$ & $1.86(1.32)$ \\
\hline $\begin{array}{l}\text { Purchase inten- } \\
\text { tions }\end{array}$ & $2.19(0.99)$ & $2.45(1.41)$ & $2.78(1.25)$ & $2.02(1.09)$ \\
\hline \multicolumn{5}{|c|}{ Experiment 2: Green Co. Paper } \\
\hline Brand attitudes & $2.29(1.07)$ & $2.02(1.22)$ & $3.40(1.59)$ & $2.10(1.34)$ \\
\hline $\begin{array}{l}\text { Purchase inten- } \\
\text { tions }\end{array}$ & $2.52(1.30)$ & $2.39(1.71)$ & $3.36(1.52)$ & $2.19(1.02)$ \\
\hline Green skepticism & $5.62(1.01)$ & $5.92(1.05)$ & $4.84(1.42)$ & $5.90(1.08)$ \\
\hline Credibility & $2.03(1.06)$ & $1.82(1.04)$ & $3.05(1.53)$ & $1.97(1.21)$ \\
\hline
\end{tabular}

\section{Appendix 3: Believability Post-Test for Claims and External Disconfirming Information}

This research assumes that consumers consider external disconfirming information as more trustworthy than company claims. In the age of fake news, however, it is possible that the traditional role of external stakeholders in guaranteeing transparency is undermined by lack of trust for unverified external claims. We thus run an independent-sample posttest to ensure that the manipulated external disconfirming information was perceived as more trustworthy than the manipulated corporate claims across all conditions.

We recruited 84 respondents $\left(M_{\text {age }}=35.15, \mathrm{SD}=11.89\right.$, $47.6 \%$ female) from MTurk. Participants were first randomly assigned to one of the four experimental conditions used in Experiment 1 (Oaky). Next, participants were asked to rate the trustworthiness of the claims $(\alpha=0.88)$ and of the external information $(\alpha=0.77)$ on a 4 -item, 7-point bipolar scale adapted from Gaziano and McGrath (1986). The procedure was repeated for the four experimental conditions used in Experiment 2 (Green Co. Paper), and measures of trustworthiness of the environmental claims $(\alpha=0.89)$ and external disconfirming information $(\alpha=0.87)$ were again recorded.

First, we run a paired samples $t$ test comparing the average trustworthiness scores for both Oaky's claims and ensuing disconfirming information. Mean scores were aggregated across experimental conditions. The results indicated that external disconfirming information was perceived as more trustworthy than Oaky's claims $\left(M_{\mathrm{EDI}}=4.53, \mathrm{SD}=1.10 \mathrm{vs}\right.$. $\left.M_{\text {Claims }}=2.83, \mathrm{SD}=1.46 ; t(83)=7.56, p<0.001\right)$. Next, we run the same analyses on the Green Co. Paper manipulations. Again, results confirmed that external disconfirming information was perceived as more trustworthy than Green Co. Paper's claims $\left(M_{\mathrm{EDI}}=4.80, \mathrm{SD}=1.27\right.$ vs. $M_{\mathrm{Claims}}=2.63$, $\mathrm{SD}=1.37 ; t(83)=9.62, p<0.001)$.
We conclude that, on average, external disconfirming information was perceived to be more trustworthy than corporate claims across all conditions. Additional analyses of variance confirmed that this heightened trustworthiness was consistent across experimental conditions, with no significant differences across cells for both Oaky $(p>0.11)$ and Green Co. Paper $(p>0.61)$.

\section{References}

Ajzen, I. (1991). The theory of planned behavior. Organizational Behavior and Human Decision Processes, 50, 179-211.

Bagozzi, R. P., Yi, Y., \& Phillips, L. W. (1991). Assessing construct validity in organizational research. Administrative Science Quarterly, 36(3), 421-458.

Balmer, J. M., Fukukawa, K., \& Gray, E. R. (2007). The nature and management of ethical corporate identity: A commentary on corporate identity, corporate social responsibility and ethics. Journal of Business Ethics, 76, 7-15.

Becker-Olsen, K. L., Cudmore, B. A., \& Hill, R. P. (2006). The impact of perceived corporate social responsibility on consumer behavior. Journal of Business Research, 59, 46-53.

Belch, G. E., Belch, M. A., Kerr, G., \& Powell, I. (2012). Advertising: An integrated marketing communication perspective. McGrawHill: North Ryde.

Bergkvist, L., \& Rossiter, J. R. (2007). The predictive validity of multiple-item versus single-item measures of the same constructs. Journal of Marketing Research, 44, 175-184.

Bless, H., \& Schwarz, N. (2010). Mental construal and the emergence of assimilation and contrast effects: The inclusion/exclusion model. Advances in Experimental Social Psychology, 42, 319-373.

Brulhart, F., Gherra, S., \& Quelin, B. V. (2017). Do stakeholder orientation and environmental proactivity impact firm profitability? Journal of Business Ethics. https://doi.org/10.1007/s1055 1-017-3732-y.

Chen, Y. S., \& Chang, C. H. (2013). Greenwash and green trust: The mediation effects of green consumer confusion and green perceived risk. Journal of Business Ethics, 114, 489-500.

do Paço, A. M. F., \& Reis, R. (2012). Factors affecting skepticism toward green advertising. Journal of Advertising, 41, 147-155.

Fabrigar, L. R., \& Petty, R. E. (1999). The role of the affective and cognitive bases of attitudes in susceptibility to affectively and cognitively based persuasion. Personality and Social Psychology Bulletin, 25, 363-381.

Federal Trade Commission (2012). Guides for the use of environmental marketing claims. Retrieved 12 September, 2017 from https ://www.ftc.gov/news-events/media-resources/truth-advertising/ green-guides.

Forbes (2017). The world's most sustainable companies 2017. Retrieved September 12, 2017 from https://www.forbes.com/ sites/jeffkauflin/2017/01/17/the-worlds-most-sustainable-compa nies-2017/\#1d15cc194e9d.

Ford, G. T., Smith, D. B., \& Swasy, J. L. (1990). Consumer skepticism of advertising claims: Testing hypotheses from economics of information. Journal of Consumer Research, 16, 433-441.

Forehand, M. R., \& Grier, S. (2003). When is honesty the best policy? The effect of stated company intent on consumer skepticism. Journal of Consumer Psychology, 13, 349-356.

Fornell, C., \& Larcker, D. F. (1981). Evaluating structural equation models with unobservable variables and measurement error. Journal of Marketing Research, 18, 39-50. 
Gigerenzer, G., \& Gaissmaier, W. (2011). Heuristic decision making. Annual Review of Psychology, 62, 451-482.

Groza, M. D., Pronschinske, M. R., \& Walker, M. (2011). Perceived organizational motives and consumer responses to proactive and reactive CSR. Journal of Business Ethics, 102, 639-652.

Hayes, A. F. (2013). An introduction to mediation, moderation, and conditional process analysis. New York: Guilford Press.

Hutton, J. G., Goodman, M. B., Alexander, J. B., \& Genest, C. M. (2001). Reputation management: The new face of corporate public relations? Public Relations Review, 27, 247-261.

Kang, C., Germann, F., \& Grewal, R. (2016). Washing away your sins? Corporate social responsibility, corporate social irresponsibility, and firm performance. Journal of Marketing, 80, 59-79.

Katsikeas, C. S., Leonidou, C. N., \& Zeriti, A. (2016). Eco-friendly product development strategy: Antecedents, outcomes, and contingent effects. Journal of the Academy of Marketing Science, 44, 660-684.

Leonidou, C. N., \& Skarmeas, D. (2015). Gray shades of green: Causes and consequences of green skepticism. Journal of Business Ethics, 144, 1-15.

Luchs, M. G., \& Kumar, M. (2017). "Yes, but this other one looks better/works better:" How do consumers respond to trade-offs between sustainability and other valued attributes? Journal of Business Ethics, 140, 567-584.

Lyon, T. P., \& Montgomery, A. W. (2013). Tweetjacked: The impact of social media on corporate greenwash. Journal of Business Ethics, 118, 747-757.

Marquis, C., \& Qian, C. (2013). Corporate social responsibility reporting in China: Symbol or substance? Organization Science, 25, 127-148.

Matthes, J., \& Wonneberger, A. (2014). The skeptical green consumer revisited: Testing the relationship between green consumerism and skepticism toward advertising. Journal of Advertising, 43, $115-127$

Minor, D., \& Morgan, J. (2011). CSR as reputation insurance: Primum non nocere. California Management Review, 53, 40-59.

Mitchell, A. A., \& Olson, J. C. (1981). Are product attribute beliefs the only mediator of advertising effects on brand attitude? Journal of Marketing Research, 18, 318-332.

Mohr, L. A., Eroğlu, D., \& Ellen, P. S. (1998). The development and testing of a measure of skepticism toward environmental claims in marketers' communications. Journal of Consumer Affairs, 32, $30-55$.

Muehling, D. D., \& Laczniak, R. N. (1988). Advertising's immediate and delayed influence on brand attitudes: Considerations across message-involvement levels. Journal of Advertising, 17, 23-34.
Muthukrishnan, A. V., Pham, M. T., \& Mungale, A. (1999). Comparison opportunity and judgment revision. Organizational Behavior and Human Decision Processes, 80, 228-251.

Nyilasy, G., Gangadharbatla, H., \& Paladino, A. (2014). Perceived greenwashing: The interactive effects of green advertising and corporate environmental performance on consumer reactions. Journal of Business Ethics, 125, 693-707.

Obermiller, C., \& Spangenberg, E. R. (1998). Development of a scale to measure consumer skepticism toward advertising. Journal of Consumer Psychology, 7, 159-186.

Ohanian, R. (1990). Construction and validation of a scale to measure celebrity endorsers' perceived expertise, trustworthiness, and attractiveness. Journal of Advertising, 19, 39-52.

Parguel, B., Benoît-Moreau, F., \& Larceneux, F. (2011). How sustainability ratings might deter 'greenwashing:' A closer look at ethical corporate communication. Journal of Business Ethics, 102, $15-28$.

Payne, J., Bettman, J. R., \& Johnson, E. J. (1991). Consumer decision making. Handbook of consumer behaviour, 50-84.

Petty, R. E., \& Cacioppo, J. T. (1986). The elaboration likelihood model of persuasion. Advances in Experimental Social Psychology, 19, 123-205.

Pham, M. T., \& Muthukrishnan, A. V. (2002). Search and alignment in judgment revision: Implications for brand positioning. Journal of Marketing Research, 39, 18-30.

Scammon, D. L. (1977). 'Information load' and consumers. Journal of Consumer Research, 4, 148-155.

Schmidt, S., \& Eisend, M. (2015). Advertising repetition: A metaanalysis on effective frequency in advertising. Journal of Advertising, 44, 415-428.

Snyder, R. (1989). Misleading characteristics of implied-superiority claims. Journal of Advertising, 18, 54-61.

Sundar, A., \& Kellaris, J. J. (2016). How logo colors influence shoppers' judgments of retailer ethicality: The mediating role of perceived eco-friendliness. Journal of Business Ethics, 146, 685-701.

Vaccaro, A., \& Echeverri, D. P. (2010). Corporate transparency and green management. Journal of Business Ethics, 95, 487-506.

van de Ven, B. (2008). An ethical framework for the marketing of corporate social responsibility. Journal of Business Ethics, 82, 339-352.

Wagner, T., Lutz, R. J., \& Weitz, B. A. (2009). Corporate hypocrisy: Overcoming the threat of inconsistent corporate social responsibility perceptions. Journal of Marketing, 73, 77-91.

Webb, D. J., \& Mohr, L. A. (1998). A typology of consumer responses to cause-related marketing: From skeptics to socially concerned. Journal of Public Policy \& Marketing, 17, 226-238. 